\title{
Evaluation of Prebiotic and Antimicrobial Properties of Natural Extracts
}

\author{
Naina Bhanjer, Prachi Bhatia, Dr. Sejal Rathod
}

Department of Biotechnology, Kishinchand Chellaram College, Mumbai, Maharashtra, India

\begin{abstract}
Article Info

Volume 8, Issue 5

Page Number : 390-398

Publication Issue

September-October-2021

\section{Article History}

Accepted : 10 Oct 2021

Published : 19 Oct 2021

Prebiotics are compounds in food that induce growth or activity of beneficial microorganisms \& are beneficial for host health. The most common example is in the gastrointestinal tract, where prebiotics alter composition of organisms in the gut microbiome. Prebiotics are the non-digestible fibers or carbohydrates that gut bacteria can digest, and prebiotics adds nutritional value $\&$ help healthy bacteria grow. Prebiotics are associated with Probiotic, microbes which keep intestine healthy and enhance immune system by fighting with harmful bacteria. This study centers on evaluation of prebiotic properties for natural, aqueous extracts of Aloe vera (Aloe barbadensis miller), Kokum dried (Garcinia indica), and Wheatgrass (Triticum aestivum) by stimulation of growth, of probiotic organism Lactobacillus casei isolated on Sterile Man Rogosa Sharpe Agar and was measured colorimetrically at $545 \mathrm{~nm}$. Antimicrobial and biopreservative study were also performed of these extracts. Hence to evaluate the variable properties of being used in cancer treatment, cosmetics, food industry, etc. Presence of Vitamin C in these plants by DCPIP method broadens the idea of Prebiotics applications, like better immune health and wound healing. Probiotic organism is also used in horticulture, in this study it resulted in enhancing the process of germination, Lactobacillus casei of $108 \mathrm{cfu} / \mathrm{ml}$ was incorporated in soil to enhance germination of fenugreek seed and kokum extract as a prebiotic source. Additionally, an online survey with Questionnaire methodology was conducted on Awareness and usage about prebiotic and probiotics by online platform and results were analyzed by graphical and statistical method.
\end{abstract}

Keywords : Prebiotic, Lactobacillus casei, Colorimetrically, Biopreservative, Germination. 


\section{INTRODUCTION}

Modern society has changed its standard of living and today health is becoming more important as in personal and social value. Consumers today are more aware of the choice of food they consume. Hence, Probiotics and Prebiotics are known for nutritional value and necessary in today's lifestyle. Probiotics are living, non-pathogenic, friendly microorganisms which play beneficial roles in the micro flora compartment of the host [2]. Lactic Acid Bacteria are the most important probiotic group of microorganisms especially Lactobacillus spp., Bifidobacterium spp. and Enterococcus spp. Dietary and therapeutic qualities of milk product are determined by probiotic microorganism. Whereas, prebiotics are the fibres utilized by good microbes, functional foods which are to be consumed to maintain health and digestion of an individual.

In 2008, the sixth Meeting of the International Scientific Association of Probiotics and Prebiotics outlined "dietary prebiotics" as "selectively fermented ingredient that leads to specific changes within the composition and/or activity of the canal microbiota, so conferring benefit(s) upon host health". The following criteria were used to classify a compound as a prebiotic: (i) it ought to be immune to acidic $\mathrm{pH}$ scale of abdomen, cannot be hydrolysed by class enzymes, and conjointly mustn't be absorbed within the GI tract, (ii) it will be fermented by intestine microbiota, and (iii) the growth or activity of the microorganism of intestine will be by stimulated by this compound and this method improves host's health [5].

Higher intake of dietary fibres plays an important role in reducing the risk of cardiovascular disease, regulating weight management and immune function, and shaping microbial. diversity in human gastrointestinal tract [15]. Probiotic organisms can work more efficiently when enhanced by prebiotics. Benefits of prebiotics for stimulating a healthy intestinal tract are well known. But there are many applications in various segments of food industry, notably dairy, beverage, processed fruit-vegetable, bakery, confectionary, extruded snack, sweetener, infant formula, pet food and livestock industry [15]. Therefore, there are many roles performed by prebiotics in day-to-day life \& thus enhances growth by improving immune response.

Multi-drug resistant bacteria are increasing and causing life-threatening infections, especially in hospitals and with patients who are immunocompromised. Hence to develop new agents, natural extracts can be a good option. Also, Biopreservation is an approach for extending shelf life of perishable horticultural commodities against microbial decay using natural or controlled microbiota and/or antimicrobial compounds [1]. In postharvest technology, application of phytochemicals and plant-based material is safe for extending storage/shelf life of fruits and vegetables.

Therefore, Aloevera, Kokum and Wheatgrass were targeted as natural sources for prebiotic, antimicrobial, and biopreservatives study. The nutraceutical properties of Aloe vera have been attributed to a glucomannan known as acemannan. Aloe vera mucilage is reported to be rich in acemannan that is a polysaccharide with a backbone of $\beta$ - $(1 \rightarrow 4)$-D-mannose residues acetylated at the C2 and $\mathrm{C}-3$ positions and contains some side chains of galactose and arabinose attached to the C-6 carbon [6]. It is also rich in Vitamin $\mathrm{C}$ and $\mathrm{E}$ content.

Wheat grass juice (WGJ) is a new vegetative beverage which is obtained from sprout of mature wheat grains (Triticum aestivum). Because of the similarity between hemoglobulin in human blood and chlorophyll molecule of plants, WGJ is called green blood. Vitamin content of WGJ supports blocking disease such as asthma and some allergenic infections [11]. WGJ also includes some flavonoid compounds such as luteolin, apigenin and quercetin. 
Due to content of this compounds WGJ helps to cure inflammatory bowel diseases in a way [15].

Kokum (Garcinia indica) is underutilized fruits which are known for their therapeutic and enhanced nutritive value and ferment the kokum juice by different yeast and lactic acid bacterial strains. Most of the fruit juices have wholesome therapeutic effect and are consumed as refreshing drinks. Due to of their acid flavor, attractive and appealing color, they are welcome addition to the table. Anthocyanin in this red dried kokum has been predicted to be potential prebiotic and has anti-inflammatory, antioxidant properties [4]. Kokum is also rich in vitamin $\mathrm{C}$ that helps slowing the signs of ageing on skin by producing collagen.

In addition, a survey was conducted on awareness, and usage about probiotics and prebiotics. An online Questionnaire methodology of 16 general questions were designed to capture the knowledge of prebiotics from different age groups, gender. It combined multiple choice and multiple selection questions with predefined answers. The survey of this kind contributes to knowledge, usage, awareness of its overall results.

\section{MATERIALS AND METHODS}

\section{A. Isolation of the Lactobacillus casei}

Isolation of Lactobacillus casei, was carried out on Sterile Man, Rogosa and Sharpe agar (MRS agar) which is a selective media for Lactobacillus species. A loopful of yakult drink was used to streak on the sterile media plate for isolation of Lactobacillus casei. In total two Plates were streaked, covered with parafilm tape to avoid contamination. One plate was kept in anaerobic chamber at Room temperature for 48-72 $\mathrm{hrs}$ and other plate was incubated at $37^{\circ} \mathrm{C}$ for 48-72 hours (As it is facultative anaerobe). After incubation growth was observed on both the plates.

\section{B. Identification of the isolates}

Biochemical tests such as Gram staining, Sugar fermentation test, oxidase test, and catalase test were performed to identify the isolate of both plates as based on Bergey's Manual of Systematic Bacteriology. As well as the isolate at $37^{\circ} \mathrm{C}$ was characterized by MALDI-TOF

\section{Culture medium and Conditions}

Following purification, a $0.1 \mathrm{ml}$ culture (adjusted to 0.1 O. D) was inoculated in $100 \mathrm{ml}$ of Sterile MRS broth was incubated at $37^{\circ} \mathrm{C}$ conditions for $48-72 \mathrm{hrs}$. Uninoculated Sterile MRS broth was used as a control.

\section{Preparation of plant extracts}

All three samples Aloevera (Aloe barbadensis miller), Wheatgrass (Triticum aestivum) and kokum dried (Garcinia indica) were surface cleansed. 50 grams of each sample was weighed using weighing machine. Extracts were extracted by two methods, aqueous and diluted acid/base pretreatment-

\section{1] By aqueous extraction}

Grinding 50 grams of each sample, with $50 \mathrm{ml}$ of $\mathrm{D} / \mathrm{W}$ each was carried out in an electrical mixer. Further the extracts were filtered with sterile Whatman filter paper No. 1 in sterile ambered bottles. The filtration process was done in sterile conditions. Later, the extracts were stored at $4^{\circ} \mathrm{C}$ till further use. These extracts were considered as 100\% concentration.

\section{2] By Diluted Acid/base pre-treatment}

Grinding each sample, weighing 50 grams, with 50 $\mathrm{ml}$ of $0.1 \mathrm{M} \mathrm{HCl}$. Neutralization of extract was done by adding dropwise $20 \mathrm{ml}$ of $0.25 \mathrm{M} \mathrm{NaOH}$. Further, filtration of extract was done by using Whatman filter paper No.1, in ambered bottles with sterile conditions and were oven dried/air dried for 5-6 hours. And weighed for yield calculation. Extracts were stored at $4^{\circ} \mathrm{C}$ until use. 
E. Evaluation of Prebiotic Properties from Aloe vera, Kokum, and Wheat grass extracts

To Evaluate prebiotic property of Aloevera, Kokum and wheatgrass, colorimetric method by stimulation growth of probiotic organism was performed [7]. Only aqueous extracts were used, as diluted acid/base pre-treatment extracts might not give valid or standard results. The culture suspension of 0.1 O.D. and $1 \%$ inulin as probiotic control were used.

Preparation of evaluating prebiotic property was performed in Sterile Side arm flasks. The inulin was added at concentration of $1 \%$ in $50 \mathrm{ml}$ MRS broth, Positive control was with $L$. casei culture and $50 \mathrm{ml}$ broth, Negative control was with $50 \mathrm{ml}$ broth. All extracts individually and with mixtures were taken $2 \mathrm{ml}$ each with $50 \mathrm{ml}$ broth, L. casei culture. After the additions, the absorbance/OD at $545 \mathrm{~nm}$ were taken initially ( 0 minute). Later flasks were kept in rotary shaker and absorbance/OD at $545 \mathrm{~nm}$ was recorded at an interval of 30 minutes.

\section{F. Investigating Antimicrobial potential of aqueous and acid/ base extracts of the selected samples}

The antimicrobial properties of plant extracts were tested against Gram-positive bacteria [Bacillus subtilis, Staphylococcus aureus], and Gram-negative bacteria [Escherichia coli, Salmonella typhi, Shigella] by agar well diffusion method.

\section{G. Studying the Bio preservative Potential of Extracts}

Aqueous extracts were tested as biopreservatives on two fruits-tomato and pear. To test the shelf life of the fruit and vegetable, controls were maintained for individual fruit with all three extracts in sterile petri dish. Further, the fruits were observed as per their texture and color, till the fruits extended their shelf life in presence of extracts.

\section{H. To Enhance the seed germination process}

Fenugreek seeds were sowed in 100 grams of soil, for control, Sample 1 and Sample 2. Only germination factor was considered in this application. Sample 1 plant of Fenugreek seeds was inoculated with $10 \mathrm{ml}$ of $0.1 \mathrm{OD}$ Lactobacillus casei culture, only probiotic organism. L. casei culture was of $10^{8} \mathrm{cfu} / \mathrm{ml}$. Sample 2 plant of Fenugreek seeds with $10 \mathrm{ml}$ of kokum extract as Prebiotic source and inoculation of $10 \mathrm{ml} 0.1$ OD Lactobacillus casei culture. Further enhancement in seed germination was noted.

\section{Studying the Presence of vitamin C content in selected Plant extracts}

Vitamin C presence was done by DCPIP titration. Few drops of DCPIP were added in a test tube with extracts were added till end point was achieved i.e., Blue to colorless.

\section{J. Conducting Survey on- Awareness \& Usage about Probiotics \& Prebiotics}

This survey was conducted to assess the awareness and usage of probiotics and prebiotics among different age groups. Survey method of Questionnaire was carried out through google forms which included questions about Probiotics and Prebiotics, food sources, roles and application.

\section{RESULTS \& DISCUSSION}

\section{A. RESULTS}

\section{Identification of Lactobacillus casei}

Lactobacillus casei is facultative anaerobe bacteria, it was grown at aerobic conditions, incubated at Room Temparture conditions. Morphology characteristics were observed as creamy white, circular, butyrous, 2-5 micrometers. Further Biochemical test- Gram nature observed was positive rods, Sugar Fermentation test for gluose, sucrose galactose, maltose, lactose and xylose were positive fermentation. Catalase test and Oxidase test was absent. Based on the Bergey's Manual of Systemic Bacteriology, and also through MALDI-TOF (By SRL Diagnostics, Mahim, Mumbai, Maharashtra) it 
was indicated that the isolated culture is Lactobacillus casei.

\section{Yield of plant extracts}

The yield of each extract and yield \% obtained was calculated.

\section{i. By aqueous extract:}

The yield of each extract was calculated by:

Yield $(\%)=\frac{\mathrm{W} 2-\mathrm{W} 1}{\mathrm{~W} 0} \times 100$, where

W2 = weight of extract with container

$\mathrm{W} 1=$ weight of blank container

$\mathrm{W} 0=$ weight of initial sample

Wherein, Aloevera, wheatgrass and Kokum extracts constituted-94.32\%, 84.32\%, 78.32\% respectively.

\section{ii. By Diluted acid/base pretreatment:}

The yield was calculated as-

Yield $(\%)=[$ Weight of crude extract $(w) /$ Weight of initial sample $(\mathrm{w} 0)] \times 100$

Where, weight of crude extract $(w)=$ Weight of extract with container (w2)- Weight of blank container $(w 1)$.

With above calculations, Aloevera, Wheatgrass, Kokum constituted 68.32\%, 60.32\%, 56.32\% respectively.

\section{Evaluation of Prebiotic Properties from selected plant extracts}

Prebiotic properties were determined colorimetrically based on stimulated growth of Probiotic organism in presence of Aqueous Plant extracts of Aloe vera, Wheatgrass and Kokum (Acid/Base pretreatment extracts were not used as it might not be suitable to evaluate plant extract for prebiotic property). The flasks were kept at Room temperature and on rotary shaker. Absorbance or Optical Density (OD) at $545 \mathrm{~nm}$ was determined at interval of 30 minutes. Inulin, which is a prominent prebiotic was maintained as control to compare the results of Plant extracts \& mixture of them, and positive, negative as well as blank (saline or $\mathrm{D} / \mathrm{W}$ ) was maintained. As L. casei is facultative anaerobe, it can grow in the presence of oxygen or without oxygen. Hence, rotary shaker was used for Lactobacillus growth, Prebiotic sources were its supplemented nutrition. Therefore, comparing extracts with inulin control at 6.5 hours, OD measured was 0.57 units, all three plant extracts showed highest activity. These all three extracts showed better results when compared to control and later can be used for supplementation as Functional foods or nutraceuticals, or beverages. [Graph 1,2 below].



Graph 1: Prebiotic activity of Individual extracts 


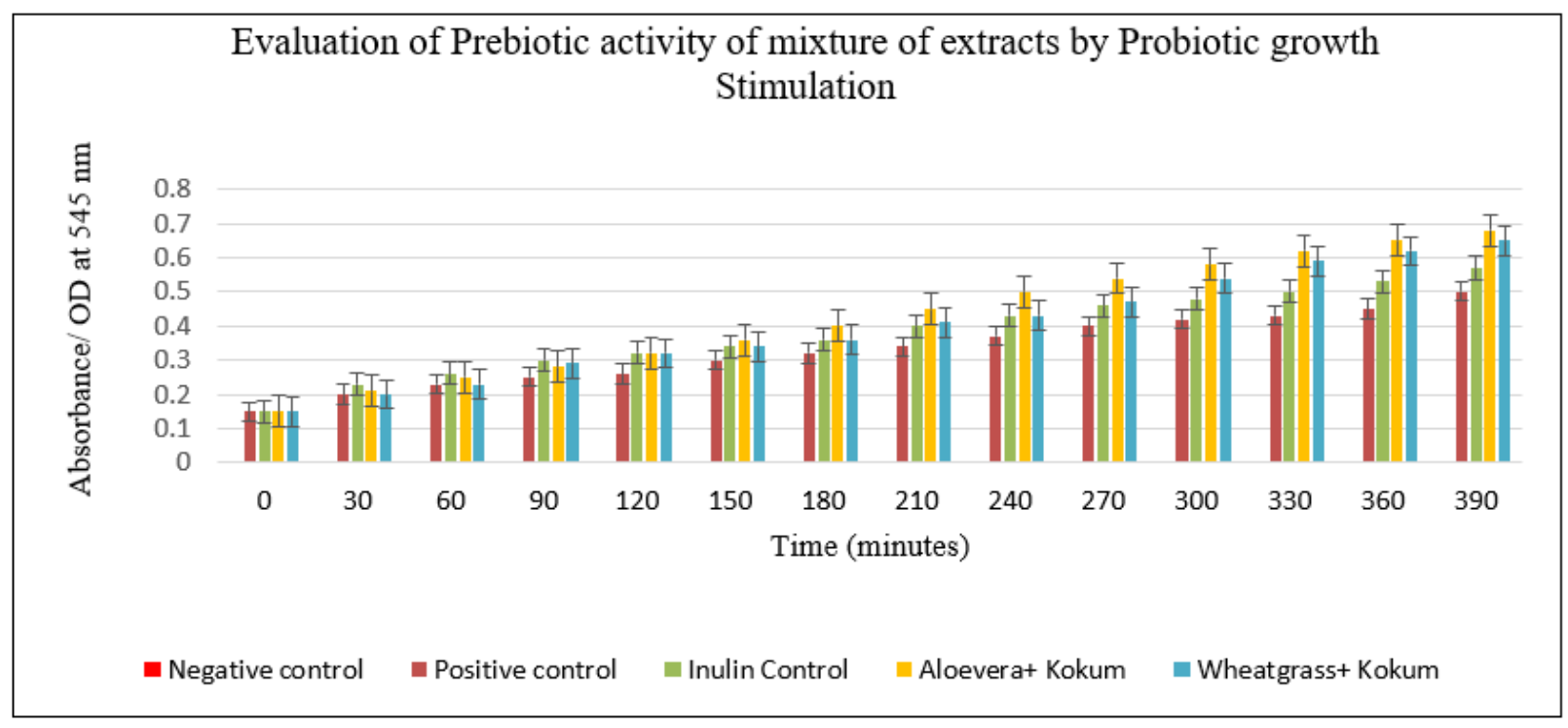

Graph 2: Prebiotic activity of Mixture of extracts

4. Investigating Antimicrobial potential of selected plant extracts

Antimicrobial activity of both aqueous and acid/base extracts of selected plant samples was investigated. Antibiotic control was maintained to compare the results. By [Graph 3], Kokum has the highest potential of antimicrobial activity in comparison to other two plant extract.

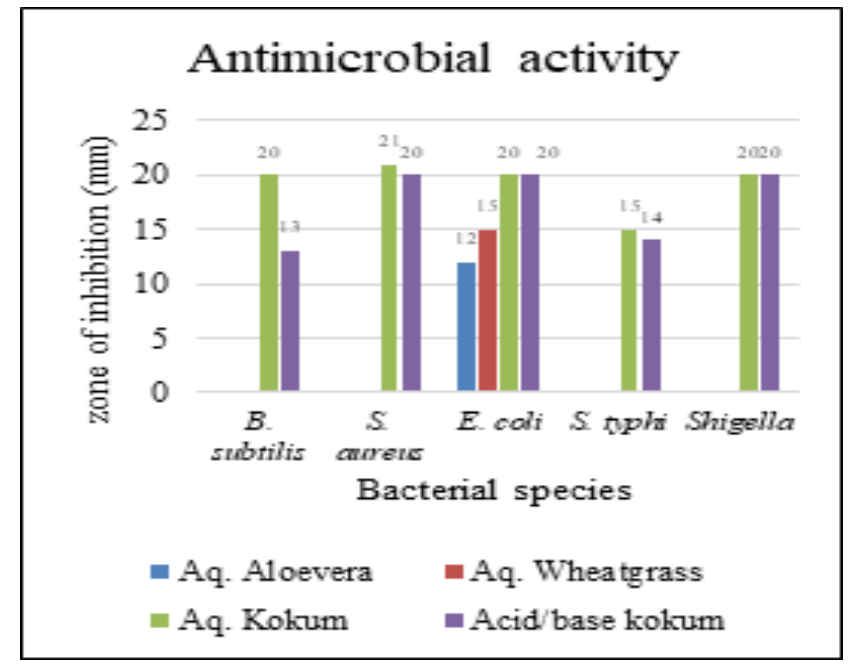

Graph 3: Antimicrobial activity

\section{Studying the Biopreservative Potential of Extracts}

Biopreservatives are the one which does not contain toxic chemical, are safe to use and will prolong the shelf life by keeping fruits, vegetables, meat, etc. the same in texture, color and taste. Evaluating Bio preservative property of aqueous extracts was studied. Extracts of Aloevera, wheatgrass increased the shelf life till four days of the study, and Kokum was observed to increase shelf life till Day eight which shows positive results as efficient bio preservative. Control fruits started to appear blackish and were appeared shrinking from Day 4-5 onwards. Kokum extract was evaluated as a better bio preservative in comparison with the Aloevera and Wheatgrass extracts.

\section{To Enhance the seed germination process}

Germination of Control fenugreek seeds was observed on sixth day of study, whereas with Lactobacillus casei culture, in Sample 1 it was observed on fifth day of study, but it was more enhanced when fortified with Kokum extract, and Lactobacillus casei culture in Sample 2. In Sample 2 sample germination was observed on fourth day of the experiment. Therefore, seed germination process was enhanced when fortified with Probiotic and Prebiotic source as nutrition. 


\section{Studying the Presence of vitamin C content in Plant extracts}

For Vitamin $C$ presence in extracts DCPIP titration method was used. Vitamin $C$ is a reducing agent which reduces this blue color dye to colorless. In all the six extracts- Aqueous and Acid/Base extracts of all three samples resulted in Vitamin $C$ presence by reducing DCPIP from blue to colorless and red in case of Kokum extract as it is red in color. Hence, these extracts can be used further in supplements of tablets, powders, juices, cosmetics, etc. as a source of Vitamin C.

\section{Survey conducted on- Awareness \& Usage about Probiotics \& Prebiotics}

By graphical and statistical analysis by Jamovi 1.6.23 where there was significant difference in variables i.e. null hypothesis was rejected and by gender-age distribution in overall survey it was evaluated that sample size was 103 responses, 69 were Females and 34 were male respondents. Highest responses for awareness of probiotics and prebiotics, food sources, roles, and their respective applications were under the age category of 18-25 and 26-40 (new youth). But there is still some lack of awareness among 41-50, 51above age categories. Whereas over all sample size when considered, knew about the key roles and key applications about probiotics and prebiotics.

\section{B. DISCUSSION}

In the present study, samples used for evaluation prebiotic property were aqueous extracts of Aloe vera (Aloe barbadensis miller), Kokum (Garcinia indica), and Wheat grass (Triticum aestivum). Lactobacillus casei culture was inoculated with St. MRS broth with these extracts individually and mixtures of extracts were measured at specific time intervals colorimetrically at $545 \mathrm{~nm}$. Kokum extract and Kokum with Aloevera extract showed the highest prebiotic activity. Previous protocol studies were referred for prebiotic activity [7].
For Aqueous Kokum extract, it exhibited $20 \mathrm{~mm}$ zone size for B. subtilis, Shigella spp. and E. coli, $21 \mathrm{~mm}$ for $S$. aureus and $15 \mathrm{~mm}$ for $S$. typhi. Acid/Base extract of Kokum exhibited $20 \mathrm{~mm}$ zone size for $S$. aureus, Escherichia coli, Shigella $14 \mathrm{~mm}$ for $S$. typhi and 13 $\mathrm{mm}$ for B. subtilis. Reported results as this study, were similar for [17] which studied antimicrobial activity of dried kokum (Garcinia inidica C).

Only aqueous Aloevera and Wheatgrass exhibited 12 $\mathrm{mm}, 15 \mathrm{~mm}$ Zone of inhibition respectively against Escherichia coli. [18] Investigated comparative study for aloevera juice and gel (leaf) extracts, where better results were obtained at different concentration. [11] Investigated on antimicrobial properties of wheatgrass juice, barley grass juice, hardaliye and boza. Where in Wheatgrass juice showed $11 \mathrm{~mm}$ of zone inhibition on St. EMB agar for E. coli. Aqueous extracts when tested as bio preservatives, Kokum increased the shelf life till Eight days of the study whereas Aloevera and Wheatgrass till four days. Control fruits started to blacken, shrink from third day of the study. [3] Studied the shelf life of Garcinia cambogia fruit for pork, $1 \%$ extract was evaluated as efficient bio preservative.

Results obtained for seed germination of fenugreek were culture of Lactobacillus casei (Probiotic) and Prebiotic source like Kokum extract enhance the seed germination by two days, germination occurs in 4-5 days whereas normally it occurs in 6 or 7 days. The extracts were found to be rich in Vitamin $\mathrm{C}$ or with the presence of Vitamin $\mathrm{C}$ by using DCPIP titration, which helps in body regulation, wound healing and these extracts could be used in food industry, cosmetics, symbiotic application, etc. as Prebiotics and Vitamin $\mathrm{C}$ rich sources.

For survey about probiotics and prebiotics, age group of $18-25$ and $26-40$ were aware the most about Prebiotics and Probiotics, Roles, applications and dietary sources. Hence, today's youth knew about 
Probiotics and Prebiotics whereas the age group of 41 and above is still getting awareness about it.

\section{CONCLUSION}

The current study concluded that natural extracts of Aloe vera (Aloe barbadensis miller), Kokum (Garcinia indica), and Wheat grass (Triticum aestivum) can be consumed as Prebiotics. The prebiotic activity was compared to inulin-prebiotic control, all the three plant extracts showed better results from the control maintained. Kokum extract and then Kokum+ Aloevera were evaluated as the highest prebiotic source amongst the three and their mixtures.

Aqueous and acid/base Extracts of Kokum has highest potential of antimicrobial activity in comparison to other two plant extracts. Even as biopreservatives, Kokum increased shelf life of tomato and pear till eighth Day of study, whereas Aloevera and wheatgrass till fourth day of study. Vitamin C presence was also indicated in all plant extracts by DCPIP titration method. For germination enhancement, Probiotic organism and prebiotic extract enhanced the germination of fenugreek seeds. Survey concluded that new youth is aware most about the roles, applications and sources of Prebiotics and Probiotics. Therefore, Kokum extract was evaluated highly fibrous and beneficiary as prebiotic, antimicrobial and biopreservatives agent.

\section{VII.ACKNOWLEDGEMENT}

The authors would like to extend sincere gratitude to the DBT Star Status grant, Jigyaasa- Science Honors Program and Kishinchand Chellaram College, Mumbai for giving the opportunity to conduct the research project with all facilities that were required. The authors appreciate SRL diagnostics, Mahim, Mumbai for conformation of isolate and the survey participants who put forward their perceptions about prebiotics and probiotics during the pandemic.

\section{REFERENCES}

[1]. Ananou S., Maqueda M., Martínez-Bueno1 M and Valdivia E., 2007, Biopreservation, an ecological approach to improve the safety and shelf-life of foods, Communicating Current Research and Educational Topics and Trends in Applied Microbiology, Volume 1, issue 2, pp. 475-487.

[2]. Betz, M \& Uzueta, A, Rasmussen H, Gregoire M, Vanderwall C, Witowich G, 2015, Knowledge, use and perceptions of probiotics and prebiotics in hospitalised patients. Nutrition \& Dietetics, Volume 72, issue 3, pp. 261-66.

[3]. Bhuvana, K. S., Mandal, P. K., and Pal U.K. 2012, Garcinia cambogia Fruit Extract Enhances the Shelf Life of Pork Fry in Room Temperature, International Journal of Meat Science, volume 2, issue 2, pp.27-33.

[4]. Coman, M.M., Oancea, A.M., Verdenelli MC, Cecchini C, Orpianesi C, Cresci A \& Silvi S (2018), Polyphenol content and in vitro evaluation of antioxidant, antimicrobial and prebiotic properties of red fruit extracts, European Food Research and Technology, Volume 244, issue 4, pp.735-745.

[5]. Davani-Davari, D., Negahdaripour, M., Karimzadeh, I., Seifan, M., Mohkam, M., Masoumi, S. J., Berenjian, A., \& Ghasemi, Y., 2019. Prebiotics: Definition, Types, Sources, Mechanisms, and Clinical Applications, Foods (Basel, Switzerland), Volume 8, issue 3, p. 92.

[6]. Gullón B, Gullón P, Tavaria, F., Alonso, J. L., \& Pintado, M., 2015, In vitro assessment of the prebiotic potential of Aloe vera mucilage and its impact on the human microbiota. Food Funct. Volume 6, Issue 2, pp.525-531.

[7]. Homayouni A, Ehsani MR, Azizidagger, A., Razavi, S. H., \& Yarmand, M.S., 2008, Spectrophotometrically Evaluation of Probiotic 
Growth in Liquid Media, Asian journal of chemistry, Volume 20, issue 3, pp. 2414-2420

[8]. Kang A, 2016, Understanding lactobacillus role in agriculture, Research \& Reviews: Journal of Ecology and Environmental Sciences, Volume 4, issue 1, pp. 24-25.

[9]. Kavitha P., Sindhuja D, and Banumathi M, 2016, Isolation and Biochemical Characterization of Lactobacillus species Isolated from Dahi, International Journal of Current Microbiology and Applied Sciences, Volume 5, issue 4, pp. 1042-1049.

[10]. Pathak M., 2013, Germinating Seeds: Source of Probiotics. World Applied Science Journal, Volume 26, issue 2, pp. 224-231.

[11]. Pehlivanoğlu H, Gündüz HH, Özülkü, G., Demirci, M., \& Demirci, M., 2015, An Investigation of Antimicrobial Activity of Wheat Grass Juice, Barley Grass Juice, Hardaliye and Boza, International Interdisciplinary Journal of Scientific Research ISSN, volume 2, issue 1 .

[12]. Sawangwan T, Wansanit W, Pattani L, Noysang C., 2018, Study of prebiotic properties from edible mushroom extraction, Agriculture and Natural Resources, volume 52, issue 6, pp. 519524.

[13]. Shah S, 2007, Dietary Factors in the Modulation of İnflammatory Bowel Disease Activity, Medscape General Medicine, volume 9, issue 1, p. 60

[14]. Silva M, Chibbar R, Walter, J., Goodman, K., Keshteli, A. H., Valcheva, R. S., \& Dieleman, L. A.,2018,A110 use of probiotics, prebiotics and dietary fibre supplements in patients with inflammatory bowel disease, Journal of the Canadian Association of Gastroenterology, volume 1, issue 2, pp. 167-168

[15]. Singla V.\& Chakkaravarthi, S., 2017. Applications of prebiotics in food industry: A review. Food science and technology international, volume 3, issue 8, 649-667.
[16]. Slavin J.2013.Fiber and prebiotics:mechanisms and health benefits. Nutrients, volume 5, issue 4, pp.1417-1435.

[17]. Sutar, R. L., Mane, S. P, \& Ghosh, J. S., 2012. Antimicrobial activity of extracts of dried kokum (Garcinia indica C). International Food Research Journal, volume 19, issue 3, pp. 12071210.

[18]. Takon IA, Ikpeme E, Victor, Odey A, Ochegbe M, 2015, Comparative study of the antimicrobial properties of aloe vera juice and gel (leaf) extracts against selected clinical isolates, International Journal of Technical Research and Applications, volume 3, issue 6, pp.108-111

[19]. Ugbe, F \& Ikudayisi-Ugbe, VA \& Amusan OT, 2017, Determination of Ascorbic Acid Concentration of Some Commercial Fruits Juices Sold in Ugbokolo Benue State, Nigeria. International Annals of Science, volume 3, Pp.19-22.

[20]. Jalal A and Ahmad N, 2019, Aloe vera as a biopreservative for keeping quality of horticultural products, Research Journal of Food Science and Nutrition, volume 4, issue 4, pp. 82-89.

\section{Cite this article as :}

Naina Bhanjer, Prachi Bhatia, Dr. Sejal Rathod "Evaluation of Prebiotic and Antimicrobial Properties of Natural Extracts", International Journal of Scientific Research in Science and Technology (IJSRST), Online ISSN : 2395-602X, Print ISSN : 23956011, Volume 8 Issue 5, pp. 390-398, SeptemberOctober 2021. Available at doi : https://doi.org/10.32628/IJSRST218556 Journal URL : https://ijsrst.com/IJSRST218556 